\title{
102 - IPA Guidelines on Dementia and Agitation: From Provisional to Final
}

Co-Chairs: Jeffrey Cummings M.D. and Mary Sano, Ph.D.

Additional Presenters: Jacobo Mintzer M.D., Paul Rosenberg M.D., and Michael Splaine

Agitation is common across neuropsychiatric disorders and contributes to disability, institutionalization, and diminished quality of life for patients and their caregivers. In 2015 IPA convened a transparent process to build a consensus definition of agitation and agreement on what elements should be included in the syndrome that resulted in publication of provisional guidelines. (Cummings et al, 2015) In the 2020-2021 year, the two co-chairs of this symposium have led a new workgroup to make the provisional consensus definition of agitation in patients with cognitive disorders that can be applied in epidemiologic, non-interventional clinical, pharmacologic, non-pharmacologic interventional, and neurobiological studies and guide treatment final.

Co-Chairs will discuss methods used in updating and findings and compare changes made to the provisional guidelines. Dr. Sano will present new findings on the biological basis of agitation in dementia and Dr. Mintzer will present on application of guidelines in the special circumstances of persons in palliative and hospice care. Dr. Rosenberg will discuss the special circumstance of agitation care in hospital emergency departments. Mr. Splaine will present findings about the utilization of the 2015 guidelines in the peer reviewed literature, professional and government dementia care guidance, and clinical trials.

Cummings, J., Mintzer, J., Brodaty, H., Sano, M., Banerjee, S., Devanand, D., . . Zhong, K. (2015). Agitation in cognitive disorders: International Psychogeriatric Association provisional consensus clinical and research definition. International Psychogeriatrics, 27(1), 7-17. doi:10.1017/S1041610214001963

\section{3 - A global perspective on dignity-based psychogeriatric care: An urgent call for a Convention on rights for older people}

\author{
Debanjan Banerjee, Kiran Rabheru, Carlos Augusto de Mendonça Lima, Gabriel Ivbijaro*
}

\begin{abstract}
The world is ageing fast with a renewed emphasis on comprehensive healthcare for older people. This has created a paradigm shift towards rights and social justice-based approach to augment the medical model of mental healthcare. Dignity is one such construct embedded into the human-rights approach. It comprises of self-respect and worthiness of an individual as well as social acceptance of his/her identity. Dignity is a multi-faceted concept and consists of privacy, independence, inclusion, autonomy, etc. It includes community participation, functional abilities, rights to sexuality and oral healthcare, outcomes which are often neglected in conventional psychogeriatric care. Ageism and fear of ageing can exacerbate social stereotypes thereby compromising dignity in older people and risk of elder abuse. Geriatric psychiatry is uniquely positioned to equip mental healthcare with a 'dignity-based' approach promoting social connectedness and health equality. This further needs integration into all levels of public health for better access and holistic psychosocial management.
\end{abstract}

With this background and on the backdrop on the unique psychosocial challenges posed by the COVID19 pandemic, this symposium glances at various dimensions of dignity-based psychogeriatric care:

- Practical approach towards dignity promotion in healthcare using an attributional model

- Perspectives, healthcare challenges and research from LMIC like Brazil and India related to dignity among older people and its impact on ageism and human rights 
- Rights-based geriatric mental healthcare in the developed nations

- Finally, an urgent call for Convention on human rights of older persons for promoting dignity in healthcare and combatting ageism

\section{INDIVIDUAL SPEAKERS \& TOPICS}

1. Promoting dignity and supporting older adults - as practical approach PRESENTER:

Professor Gabriel Ivbijaro MBE JP

(MBBS, MMedSci MA, PhD, FRCGP, FWACPsych, IDFAPA)

AFFILIATIONS:

1. Professor, NOVA University, Lisbon, Portugal

2. Honorary Visiting Fellow, Faculty of Management, Law and Social Sciences, University of Bradford, UK

3. President, The World Dignity Project

4. Secretary General, WFMH

5. Medical Director, The Wood Street Medical Centre, London, UK

2. The respect of dignity in the mental health care of Brazilian older adults. PRESENTER:

Dr.Carlos Augusto de Mendonça Lima (M.D., MSci., DSci.)

AFFILIATION:

Chair, WPA Section of Old Age Psychiatry

3. Dignity-based mental healthcare among older people in the world's largest ageing democracy: A slippery slope forward

PRESENTER:

Dr. Debanjan Banerjee (MD, DNB, MNAMS, DM)

AFFILIATION:

Consultant Geriatric Psychiatrist, Kolkata, India

\section{Ageism-Need for a Convention on the rights of older persons} PRESENTER:

Dr. Kiran Rabheru (MD, CCFP, FRCP, DABPN)

AFFILIATION:

Geriatric Psychiatrist, TOH

Professor of Psychiatry, U of Ottawa

Chair, Steering Group, GAROP

Chair of the Board, ILC-Canada

*The authors of this abstract have been added. An addendum detailing this change has also been published (doi: 10.1017/S1041610222000023). 